\title{
The Influence of Chemically Pre-treated Chestnut Waste and Pinecone Filler Content on the Properties of Polyester Composites
}

\author{
Alev Akpinar Borazan*, Duygu Gokdai, Caglayan Acikgoz, Gunce Alp Adiguzel \\ Chemical and Process Engineering, Bilecik Seyh Edebali University, Turkey
}

Copyright@2017 by authors, all rights reserved. Authors agree that this article remains permanently open access under the terms of the Creative Commons Attribution License 4.0 International License

\begin{abstract}
There is critical concern about meeting future global demand for materials because of the depletion of natural resources. In particular, the balance between future demand and sustainable supply will require a great deal of attention in years to come. The interest in the long term sustainability of material resources has led to advancements in bio-composite or polymer composite materials that are made from natural fibers and resin. Pinecones and chestnut waste are most often used as the biomass/biochar source. Nature proposes, and man disposes; we have to find or create new forms of pinecone and chestnut waste to increase their value and for environmental reasons. That is why the current waste was processed and transformed to filler in an up-graded state. In this study, composites were manufactured using chestnut waste and pinecone powder as filler and polyester as the polymer matrix. In addition, methyl ethyl ketone peroxide as hardener and cobalt naphthenate as accelerator were used to produce polyester composite. Raw materials of the fillers were treated with sodium hydroxide solution. The polyester amount was kept constant while the filler ratio was increased from $3 \%$ to $12 \%$ by weight. The similarities and differences between composites with different fillers and chemical pre-treatments were assessed by evaluating certain mechanical properties such as flexural strength, elastic modulus and hardness and various physical features such as density, open porosity percentage and water absorption. According to the experimental results, increasing the ratio of both chestnut and pinecone powder led to a decrease in the bending strength and an increase in the elastic modulus. Higher properties were associated with the chestnut waste/polyester composite than the pinecone powder/polyester composite.
\end{abstract}

Keywords Sustainability, Polyester Composite, Pinecone Powder, Chestnut Waste, Bending Properties, Physical Properties

\section{Introduction}

Evidence of the worldwide depletion of natural resources has resulted in critical concern about meeting future global demand. Maintaining a balance between future demand and sustainable supply is the next challenge. Composites have become an important part of daily life for virtually everyone. In addition to increasing fuel prices, there is much pressure from environmental groups and government agencies to find other means of creating composites with more environmentally friendly processing methods and materials $[1,2]$. Today, rapid technological change and increased competition in many industries necessitate lighter and stronger materials for use in high-performance products [3, 4]. Composite structures that can provide the desired properties are created when polymers that do not meet some of the necessary physical and/or chemical characteristics in the application fields are supported by fibers of various types and proportions $[5,6]$. However, the use of natural fibers and shells instead of textile fibers has become mandatory in recent years. This is because the recycling of reinforcing elements made from fibrous textiles that are used as supports for composite materials is difficult, their fragmentation lifetimes in nature are long and production costs are high [7]. For the alleviation of these problems and more efficient use of agricultural waste, the production and use of natural fiber-reinforced composites by supporting bast fibers of polymers that are generally in the class of cellulosic herbal fibers with natural fibers such as those from fruit and leaves has become widespread [8]. The use of natural fibers in composite materials is increasing rapidly as concepts such as recycling and sustainability gain importance. The biological degradability and recyclability of the natural fibers used as reinforcing materials make them preferable to synthetic fibers thanks to their low density and high specific strength values as well as the renewability of their herbal natural resources. Thus, the components that make up the material become increasingly important for the development of 
composite materials with different properties [9, 10]. Through their research, Fiore and colleagues showed that artichoke fibers can be used as a valid alternative to glass fiber in composite materials [11]. In another study conducted by Sewench and colleagues in 2013, increasing the amount of filler in the production of epoxy composites with chestnut shell filler improved some mechanical, thermal and dielectric properties [12]. On the other hand, research by Chensong and friends in 2011 found that the visible gaps of polyester composite samples reinforced with macadamia nut shell particles grew with increasing reinforcement but their bending properties changed little. However, studies done by $\mathrm{Wu}$ and colleagues show that composite materials obtained from chestnut husk fiber (CSF) and polyhydroxy alkynoate (Pha) are biodegradable and biocompatible [13, 14]. Turkey has major production potential because the climate and soil properties of the country are suitable for the cultivation of chestnuts. According to FAO and TUIK data, the People's Republic of China alone was responsible for 1,650,000 of the $1,998,880$ tons of world chestnut production in 2013 [15]. China's share of world production exceeds $82.5 \%$. South Korea comes second with 70,000 tons and Turkey third with 60,000 tons. In this study, increasing amounts of chestnut shell waste and pinecone powder were used as reinforcement materials in the production of a polyester composite that was manufactured in the laboratory with a metal casting mold. Additionally, the effect of chemical treatment of fibers by alkalization on the bending and physical properties of a polyester matrix composite reinforced with natural fibers was examined.

\section{Materials and Methods}

\subsection{Materials, Alkali Treatment of Fiber and Composite Manufacturing}

In this study, polyester resin was used as the matrix material. The filling material of discarded chestnut shells was obtained from the chestnut candy company in Bursa/Turkey while pinecones were collected from the university garden. Polyester resin (Polipol383-G) with a density of $1.076 \pm 0.05 \mathrm{~g} / \mathrm{cm}^{3}$ used in the main matrix was obtained from Poliya Composite Resins \& Polymers Inc. Fillers were first dried in laboratory conditions then ground with a hammer mill and sieved. After separation into two parts, one part was treated with $\mathrm{NaOH}, 1.6 \mathrm{~mol} / \mathrm{l}$ concentration, the fibers were immersed for 24 hours and then the fiber was rinsed using distilled water until it attained a $\mathrm{pH}$ of 7. Fibers were then filtered in a Buchner funnel and dried in the oven at $105^{\circ} \mathrm{C}$. As fillers, ground chestnut shell, pinecone powder and their chemically treated constituents were used individually for composite manufacturing. The theoretical densities of fillers were determined using a Micromeritics brand AccuPyc II 1340 model Helium-gas pycnometer (Table 1). After immersion for about two hours, the wood fiber was rinsed using distilled water until it attained a $\mathrm{pH}$ of 7.

The flow chart for the production of the polyester composite is shown in Figure 1. 2\% Cobalt solution was used as an accelerator in the mixtures. For curing, methyl ethyl ketone peroxide (MEKP, Akzo Nobel Products) with a resin to hardener ratio of $2 / 100 \mathrm{wt} \%$ was added. The filler percentage was based on the recommended filler concentrations related to wood composites in the literature. Polyester and prepared fillers were weighed in the proportions specified in the recipe (Table 2).

The fillers were blended for five minutes at speeds of 500, 1000 and $1500 \mathrm{rpm}$, respectively using a mechanical stirrer (Stuart scientific stirrer SS3, UK). After a homogeneous mixture was obtained the specified amount of the accelerator and hardener was added. The mixture was poured into molds (see Figure 2) and the preliminary cure was done at room temperature for 24 hours. $10 \mathrm{~mm}$ x $4 \mathrm{~mm}$ x $100 \mathrm{~mm}$ slabs were removed from the mold. This was followed by post cure in an oven at $105^{\circ} \mathrm{C}$ for two hours.

Table 1. Filling materials theoretical density and volume

\begin{tabular}{|c|c|c|}
\hline Material & Mean Density $\left(\mathrm{g} / \mathrm{cm}^{3}\right)$ & Mean Volume $\left(\mathrm{cm}^{3}\right)$ \\
\hline Pinecone Powder & $1.4179 \pm 0.0008$ & $1.9555 \pm 0.0011$ \\
\hline Chemically Treated Pinecone Powder & $1.4492 \pm 0.0007$ & $1.8737 \pm 0.0009$ \\
\hline Ground Waste Chestnut Shell & $1.4722 \pm 0.0007$ & $2.2621 \pm 0.0011$ \\
\hline Chemically Treated Ground Waste Chestnut Shell & $1.5248 \pm 0.0007$ & $1.7273 \pm 0.0008$ \\
\hline
\end{tabular}




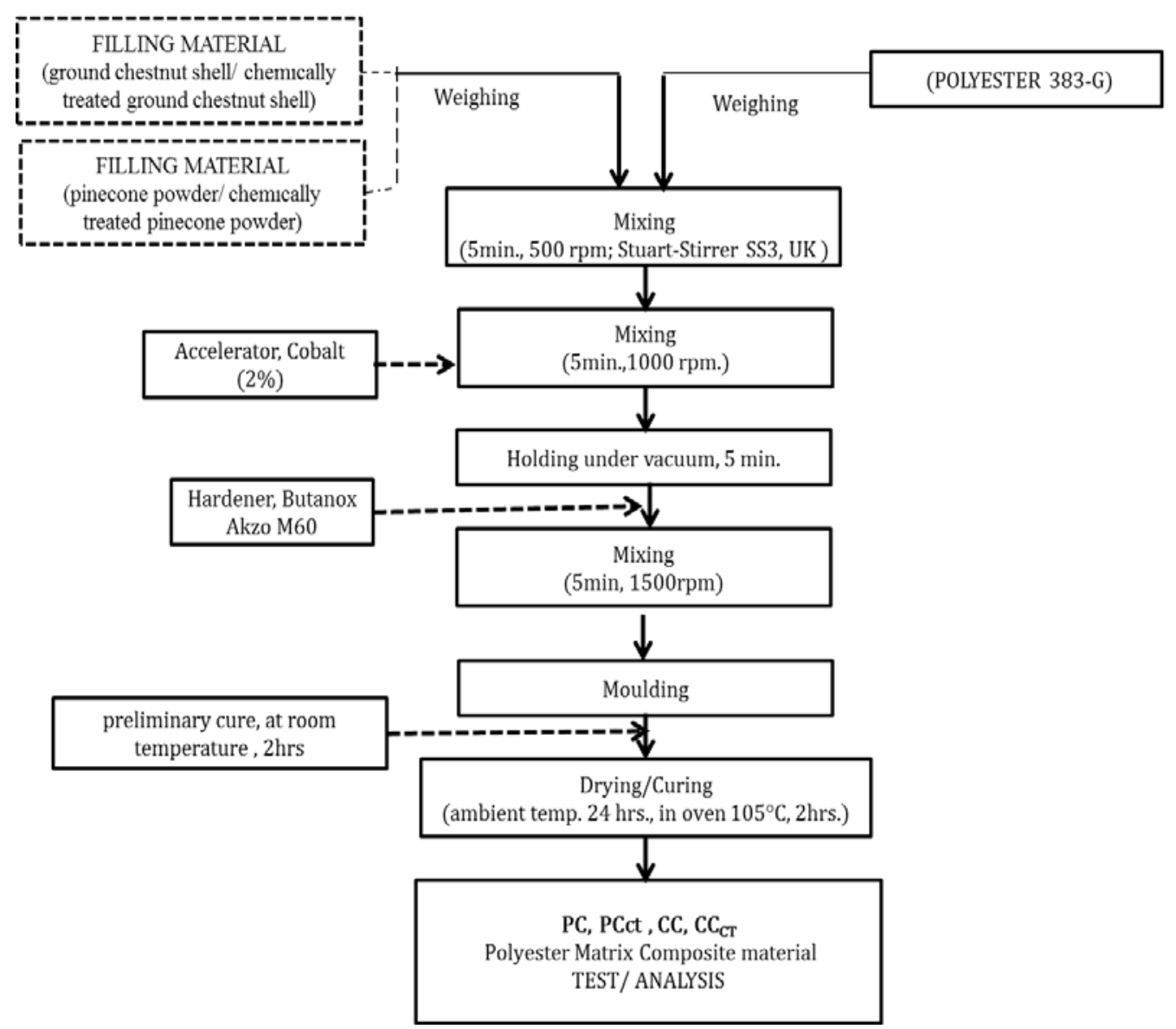

Figure 1. Simplified flow chart for the manufacturing process of polyester composite

Table 2. Detailed designation and composition of composites

\begin{tabular}{|c|c|c|c|c|}
\hline \multicolumn{2}{|l|}{ Sample Code } & \multicolumn{2}{|c|}{$\begin{array}{c}\text { Filler } \\
*[w t \%]\end{array}$} & \multirow{3}{*}{$\begin{array}{c}\begin{array}{c}\text { Polyester } \\
*[w t \%]\end{array} \\
94\end{array}$} \\
\hline & & $* * \mathbf{P}$ & ${ }^{* *} \mathrm{C}$ & \\
\hline \multirow{3}{*}{ Pinecone powder/polyester Composites } & PC1 & 6 & 0 & \\
\hline & PC2 & 9 & 0 & 91 \\
\hline & PC3 & 12 & 0 & 88 \\
\hline \multirow{3}{*}{$\begin{array}{l}\text { Chemically treated Pinecone powder/polyester } \\
\text { Composites }\end{array}$} & PC1ct & 6 & 0 & 94 \\
\hline & PC2ct & 9 & 0 & 91 \\
\hline & PC3ct & 12 & 0 & 88 \\
\hline \multirow{3}{*}{ Ground Chestnut shell/polyester Composites } & CC1 & 0 & 6 & 94 \\
\hline & CC2 & 0 & 9 & 91 \\
\hline & CC3 & 0 & 12 & 88 \\
\hline \multirow{3}{*}{$\begin{array}{l}\text { Chemically Ground Chestnut shell/polyester } \\
\text { Composites }\end{array}$} & CC1ct & 0 & 6 & 94 \\
\hline & CC2ct & 0 & 9 & 91 \\
\hline & CC3ct & 0 & 12 & 88 \\
\hline
\end{tabular}

*[wt\%]: Weight percent,**P: pinecone powder. C: Ground Chestnut shell. ct: Chemically treated material 


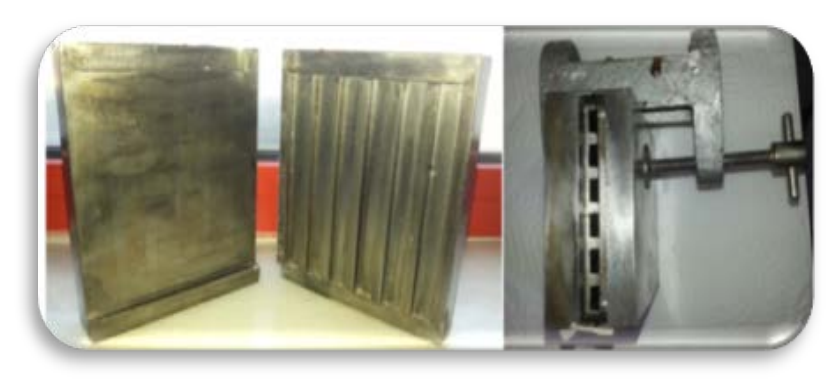

Figure 2. Photographs of the mold

\subsection{Experimental Method}

The mechanical and physical properties of the composite materials were determined by applying a three-point bending test, shore-D hardness test and water absorption tests. The results of the analysis were calculated based on the average value of five specimens for each composition.

The flexural properties of the material were determined with a Shimadzu AG IC100 kN with a three point bending test (according to EN ISO178). Five specimens for each composition were tested at a cross head speed of 2 mm.min-1. The length, width and thickness of the test specimens were 100, 10 and $4 \mathrm{~mm}$, respectively. The indentation hardness of the material was measured by shore-D. The Izod impact test was conducted with a DVT CD from Devotrans Quality Control Test Instruments Ltd. Flexural strength and modulus in the composite was calculated using the following equations:

$$
\begin{gathered}
\sigma=(3 L P) /\left(2 b d^{2}\right) \\
E_{\mathrm{f}}=\left(\mathrm{L}^{3} \mathrm{~m}\right) /\left(4 \mathrm{bd}^{3}\right)
\end{gathered}
$$

where $\sigma$ is flexural strength $\left(\mathrm{N} / \mathrm{mm}^{2}\right), E_{\mathrm{f}}$ is flexural modulus (MPa), $\mathrm{L}$ is the support span (mm), $\mathrm{P}$ is the maximum load $(\mathrm{N}), \mathrm{b}$ is the width of the composite sample (mm), $\mathrm{d}$ is the thickness of the composite sample ( $\mathrm{mm}$ ) and $\mathrm{m}$ is the slope of the initial straight line portion of the load-displacement curve.

The water absorption test was carried out using the weighting method to find the water uptake by the composites (according to ASTM D 570 standard). The samples were weighted by balancing to obtain the mass of the sample before soaking it in water. The values were recorded and then the samples were left in a beaker containing boiling distilled water for two hours then at room temperature for 24 hours to establish how much water had been absorbed. Then, they were removed from the beaker. A kit comprising an analytical scale and a weighting jig was used to weigh a sample of the material in air and fluid. The different values before and after soaking are defined as the percentage of water absorption:

$$
\mathrm{A}, \%=(\mathrm{W}-\mathrm{D}) / \mathrm{D} * 100
$$

$$
\begin{aligned}
\mathrm{B} & =[\mathrm{D} /(\mathrm{W}-\mathrm{S})]^{*} \rho_{\text {water }} \\
\mathrm{P}, \% & =[(\mathrm{W}-\mathrm{D}) /(\mathrm{W}-\mathrm{S})]^{*} 100
\end{aligned}
$$

where $\mathrm{W}$ is saturated weight, $\mathrm{S}$ is suspended weight, $\mathrm{D}$ is dry weight, $\mathrm{A}$ is water absorption, $\mathrm{B}$ is bulk density and $\mathrm{P}$ is apparent porosity.

\section{Results and Discussion}

A study was made of the fracture behavior of alkali-treated ground chestnut shell and pinecone powder fiber composites under a three point bend. The effects on the fibers of immersion in $\mathrm{NaOH}$ were studied and the effects on the fiber surface morphology and the composite's flexural strength were analyzed and discussed. The scanning electron microscope (SEM., Zeiss Supra 40VP, Germany) photographs of the morphology of both untreated and alkalized surfaces are shown in Figure 3.

It appears that the fiber surface of the untreated filler material is covered with an unevenly distributed layer that can probably be assigned to non-cellulose compounds (like waxy substances, oil and impurities).

Following the alkali treatment, the pores became visibly clearer, which may be due to the leaching out of waxy substances and impurities from the surface of the fiber. Alkali treatment also leads to fiber bundle fibrillation, which increases the effective surface area available for contact with the wet matrix [16, 17]. Applying both the ground waste chestnut shell powder and the pinecone powder to the chemical process in the production of composite materials resulted in little decrease in the bulk density. The chemical process applied both to the cones and to the chestnut shell powder led to a visible change in porosity in the production of composite materials prepared with increasing reinforcement filler. The open porosity in the chemical process using waste cone dust increased with increasing supplementation in composite samples. The open porosity reached $25 \%$ in samples with the highest dust cone PC3ct percentage. A different situation developed in composites to which the waste chestnut shells were added. The open porosity increased with the application of the chemical operation and with increasing amounts of reinforcement. However, this increase dropped depending on the increased rate of reinforcement (Table 3 ).

Utilization of an alkali can lead to the deterioration of glycosidic and ester side chains. As a result of this breakage the lignin structure can change and cellulose swelling can occur as can decrystallization of cellulose. Sodium hydroxide has a positive effect on biomass because it can collapse its lignin structure and provide the connection between enzymes, cellulose and hemicellulose [18]. 

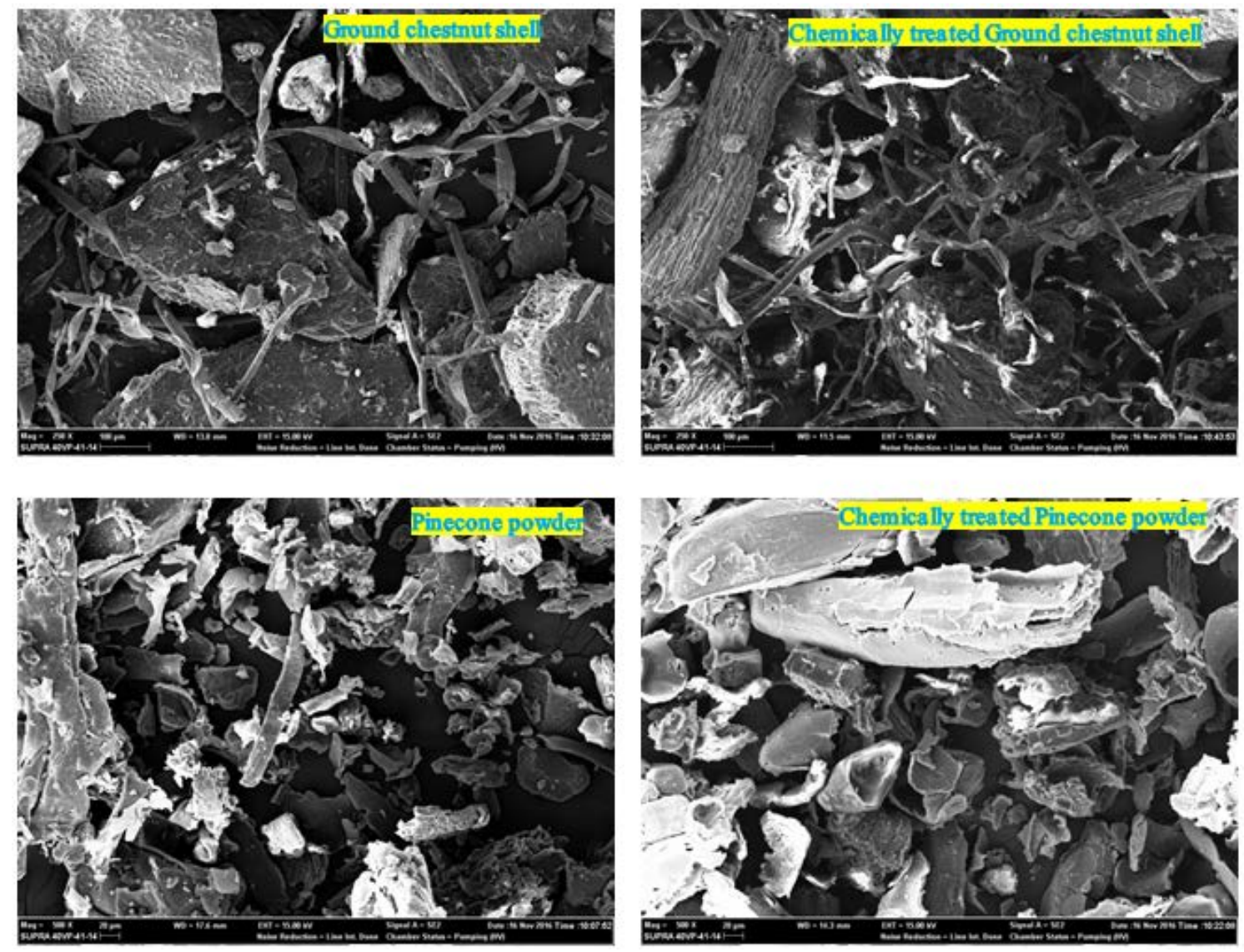

Figure 3. SEM micrographs of fillers chemically treated and untreated

Table 3. Effect of various filler loadings and chemical pretreatment on density and dimensional properties of composite samples

\begin{tabular}{|c|c|c|c|}
\hline Sample code & Bulk Density (g/cm³) & Apparent Porosity (\%) & $\begin{array}{c}\text { Water Absorption, } \\
\text { 24hrs (\%) } \\
\end{array}$ \\
\hline PC1 & $1.19 \pm 0.04$ & $1.86 \pm 0.10$ & $1.38 \pm 0.03$ \\
\hline PC2 & $1.19 \pm 0.04$ & $1.92 \pm 0.20$ & $1.56 \pm 0.05$ \\
\hline PC3 & $1.19 \pm 0.03$ & $1.94 \pm 0.40$ & $1.64 \pm 0.06$ \\
\hline PC1ct & $1.18 \pm 0.08$ & $2.06 \pm 0.02$ & $1.75 \pm 0.10$ \\
\hline PC2ct & $1.17 \pm 0.05$ & $2.25 \pm 0.05$ & $1.9 \pm 0.30$ \\
\hline PC3ct & $1.16 \pm 0.04$ & $2.44 \pm 0.07$ & $2.25 \pm 0.40$ \\
\hline CC1 & $1.19 \pm 0.10$ & $1.88 \pm 0.10$ & $1.58 \pm 0.04$ \\
\hline CC2 & $1.18 \pm 0.06$ & $2.39 \pm 0.40$ & $2.02 \pm 0.06$ \\
\hline $\mathrm{CC} 3$ & $1.18 \pm 0.04$ & $3.12 \pm 0.20$ & $2.63 \pm 0.07$ \\
\hline CC1ct & $1.19 \pm 0.10$ & $2.37 \pm 0.02$ & $2.00 \pm 0.08$ \\
\hline CC2ct & $1.19 \pm 0.10$ & $2.51 \pm 0.02$ & $2.12 \pm 0.06$ \\
\hline CC3ct & $1.18 \pm 0.20$ & $3.05 \pm 0.06$ & $2.59 \pm 0.09$ \\
\hline
\end{tabular}



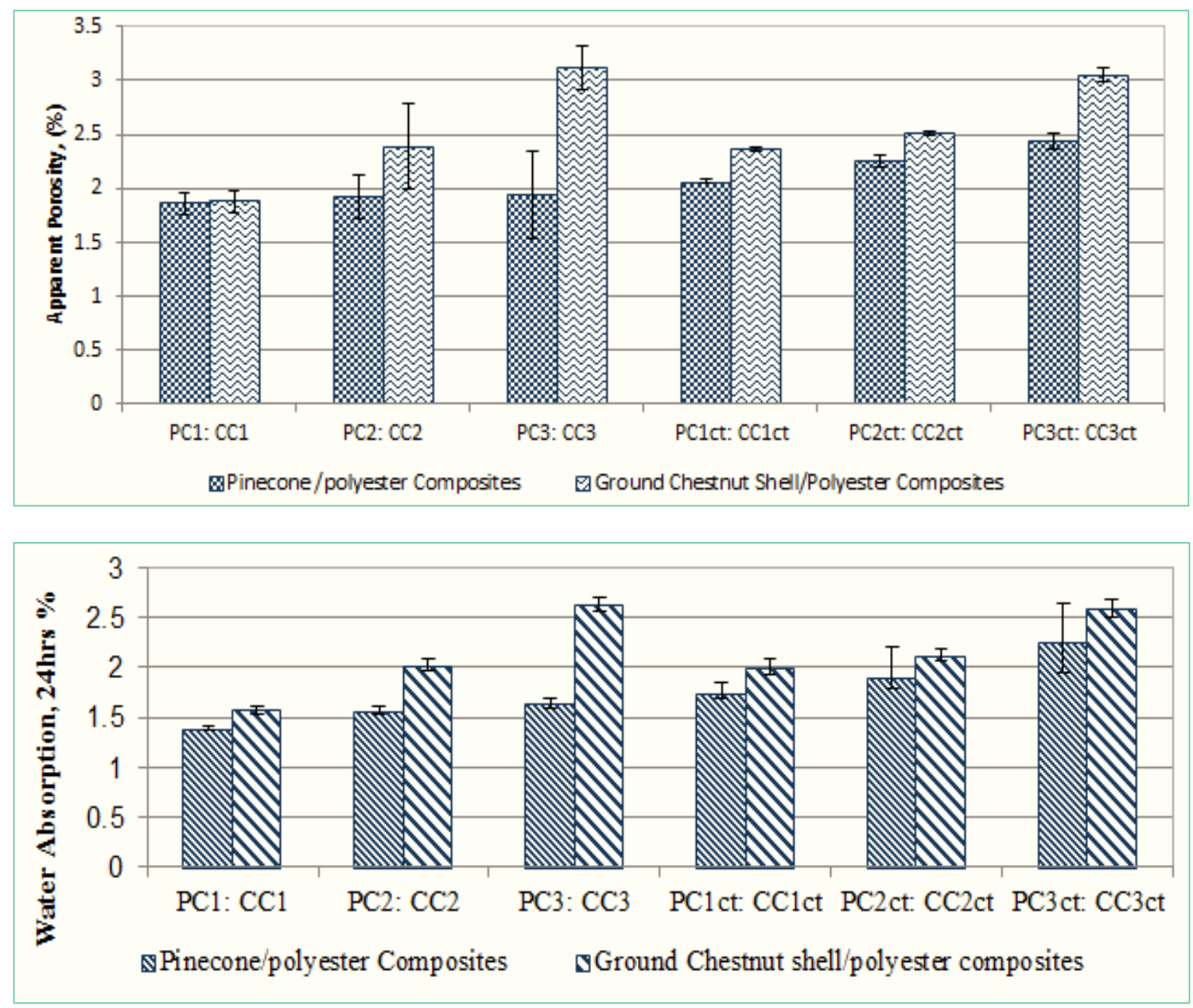

Figure 4. Changes of the dimensional properties of polyester composites by different filler, filler ratio and pretreatment

When the 24-hour water absorption results of polyester composite samples were reviewed, it was observed that they had a parallel development with the results of the open porosity. The chemical process applied to filler materials increased the amount of water absorption. Additionally, the chemical process applied to chestnut shells showed a positive effect and it was possible to gradually reduce this decline with the addition of increasing amounts of fillers (Table 3, Fig 4). This is thought to have originated due to the hydroxyl groups of cellulose fibers and the connection between water molecules by hydrogen bonding. While water absorption only occurs at the surface for glass fibers, cellulose fibers can have thorough interaction with water because of their bulk structure. Attention should be paid to the relative humidity of the surrounding atmosphere, purity of cellulose and degree of crystallinity when evaluating the quantity of water absorbed by composites [19].

Application of the chemical process to both the pinecone powder and ground waste chestnut shell content of composite materials was effective at different levels on impact resistance and hardness values. Increased rates of the cones and the pretreatment application caused a decrease in impact resistance and hardness values. However, ground waste chestnut shell / polyester composite applications were positively affected by increasing the rate of reinforcement and the pre-treatment operation. An increase in the impact resistance and hardness values was observed (Table 4, Figure 5).

The maximum strength needed to break the specimen in the bending test showed an increase in the powder waste of pinecones and a decrease in chestnut shells depending on the reinforcement ratio. It was observed that lower forces were needed for samples produced with cone filler as opposed to higher forces needed for samples produced with chestnut waste for the breakage of polyester composite samples through the use of chemical processing supplements. 
Table 4. Some mechanical properties of composite samples

\begin{tabular}{|c|c|c|c|c|c|}
\hline Sample code & $\begin{array}{c}\text { Max Force } \\
\mathbf{N}\end{array}$ & $\begin{array}{c}\text { Flexural Strength } \\
\mathbf{N} / \mathbf{m m}^{2}\end{array}$ & $\begin{array}{c}\text { Flexural modulus } \\
\mathbf{M P a}\end{array}$ & $\begin{array}{c}\text { Izod impact strength }\left(\mathbf{J} / \mathbf{m m}^{2}\right) \\
\text { Hardness, } \\
\text { Shore-D }\end{array}$ \\
\hline PC1 & $109.38 \pm 3.20$ & $59.46 \pm 2.57$ & $5,337.43 \pm 0.13$ & $5.27 \pm 0.83$ & $88 \pm 0.10$ \\
\hline PC2 & $118.75 \pm 3.46$ & $66.33 \pm 2.69$ & $5,187.55 \pm 0.23$ & $5.12 \pm 0.75$ & $87 \pm 0.14$ \\
\hline PC3 & $125.00 \pm 3.65$ & $71.69 \pm 3.11$ & $4,667.39 \pm 0.27$ & $5.02 \pm 0.72$ & $86 \pm 0.12$ \\
\hline PC1ct & $103.13 \pm 3.57$ & $53.59 \pm 2.80$ & $5,726.75 \pm 0.10$ & $5.14 \pm 0.44$ & $85 \pm 0.89$ \\
\hline PC2ct & $106.25 \pm 4.12$ & $56.49 \pm 2.65$ & $5,627.46 \pm 0.18$ & $4.96 \pm 0.52$ & $86 \pm 0.77$ \\
\hline PC3ct & $115.63 \pm 4.18$ & $64.66 \pm 2.43$ & $5,089.82 \pm 0.22$ & $4.64 \pm 0.55$ & $87 \pm 0.72$ \\
\hline CC1 & $146.88 \pm 3.45$ & $89.15 \pm 4.35$ & $2,984.32 \pm 0.15$ & $4.76 \pm 0.31$ & $84 \pm 0.34$ \\
\hline CC2 & $143.75 \pm 3.68$ & $77.61 \pm 4.66$ & $3,299.57 \pm 0.24$ & $5.00 \pm 0.38$ & $87 \pm 0.46$ \\
\hline CC3 & $128.13 \pm 3.90$ & $72.20 \pm 4.92$ & $3,369.73 \pm 0.31$ & $5.30 \pm 0.43$ & $88 \pm 0.58$ \\
\hline CC1ct & $150.00 \pm 4.67$ & $87.68 \pm 4.88$ & $3,487.71 \pm 0.33$ & $5.24 \pm 0.21$ & $88 \pm 0.36$ \\
\hline CC2ct & $143.75 \pm 5.31$ & $74.13 \pm 4.97$ & $3,576.19 \pm 0.39$ & $6.65 \pm 0.19$ & $89 \pm 0.49$ \\
\hline CC3ct & $131.25 \pm 5.28$ & $70.90 \pm 5.02$ & $3,669.24 \pm 0.41$ & $6.89 \pm 0.15$ & $91 \pm 0.66$ \\
\hline
\end{tabular}
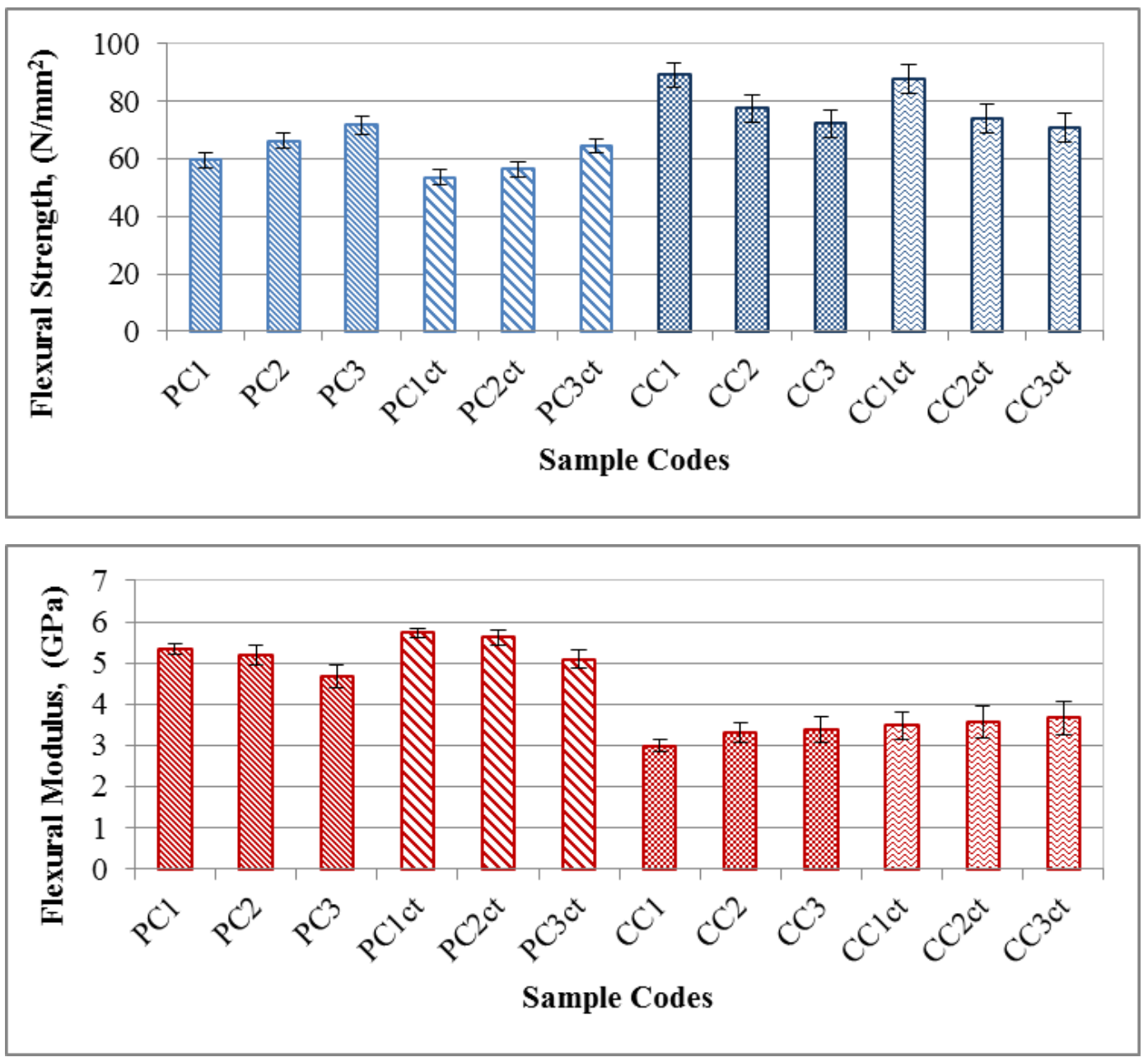

Figure 5. Changes of the mechanical properties of polyester composites by different filler, filler ratio and pretreatment

The effect of increasing the reinforcement ratio was determined according to the results obtained with a three-point bending test. The flexural strengths of composite samples with pinecone powder fillers increased. In spite of this, the flexural strength results of ground waste chestnut composite samples showed a decline. The increasing reinforcement ratio caused a reverse effect in the bending module. Also, results showed that the chemical application caused a reduction in flexural strength but increased the flexural modulus values of the composite samples in which 
both ground waste chestnut shell and pinecone powder were used.

\section{Conclusions}

As illustrated by the literature presented in this paper, many studies report that lignocellulosic materials are increasingly being applied as fillers of polymer composites. Production of composites of very good macroscopic properties is not easy and many aspects need to be considered. As a conclusion, chemical pre-treatment improved physical and mechanical properties in polyester composite samples of waste chestnut shell powder while it had a negative impact on the composite polyester sample of pinecone powder. One of the more important problems is insufficient adhesion between the phases of the polymer matrix and the lignocellulosic filler [20, 21]. It is thought that neither filler provided the desired mechanical effects because of the incompatibility of the hydrophilic character of the natural fibers with the hydrophobic properties of a polymer matrix. This can be solved by different types of chemical or physical modification of the composite components. The use of the coupling agent is intended to enhance the interaction between phases in the continuation of the study. In addition to the physical and mechanical properties, the filler amount influences the cost of the product. By lowering the resin content in the particle filled composite costs can also be lowered. Resin is relatively expensive compared to other kinds of fillers. This is the main motivation that leads manufacturers to seek methods to lower the filler content [22].

Successful commercialization of chestnut shell \& pinecone/polyester composite products depends on the development of a cost-effective manufacturing process on a commercial scale and the establishment of a market base for sustainable products. This will also lead to reducing and preventing waste.

\section{REFERENCES}

[1] A.M.M. Al Bakri, G.C.M. Ruzaidi, M.N. Norazian, J. Liyana. Preliminary Study on Bagasse Fibre With Polystyrene As A Polymer Composites. International Conference on Environmental Research and Technology (ICERT), 2008.

[2] S. Otles, S. Despoudi, C. Bucatariu, C. Kartal. Food Waste Management Valorization and Sustainability in The Food Industry, Food Waste Recovery, Processing Technologies and Industrial Techniques.

http://dx.doi.org/10.1016/B978-0-12-800351-0.00001-8, 3-23, Academic press. (2015).

[3] D.J. Gardner, Y. Han, W. Song. Wood plastic composites technology trends. Proceedings of the 51st International Convention of Society of Wood Science and Technology, 2008.
[4] V. Nagarajan, A.K. Mohanty, M. Misra. Sustainable Green Composites: Value Addition to Agricultural Residues and Perennial Grasses, ACS Sustainable Chemistry\& Engineering, Vol.1, No.3, 325 - 333, 2013.

[5] P.A Fowler, J.M. Hughes, R.M. Elias. Biocomposites: technology, environmental credentials and market forces, Journal of the Science of Food and Agriculture, Vol.86, No.12, 1781-1789, 2006.

[6] T. Karpenja, A. Lorentzon, K. Wickholm. Sustainability aspects in waste management of biocomposites, 26th IAPRI symposium on packaging, 220-232, 2013.

[7] J. Lampinen. Biocomposite research as a way to add value and sustainability to composites. Proceedings of the 4th Wood Fibre Polymer Composites International Symposium, 2009.

[8] M.C. Santos Ribeiro, A. Fiúza, A. Ferreira, M. Lurdes Dinis A.C. Meira Castro, J. P. Meixedo, M.R. Alvim Recycling Approach towards Sustainability Advance of Composite Materials’ Industry, Recycling, Vol.1, No.1, 178-193, 2016.

[9] T. Huber, J. Müssig, O. Curnow, S. Pang, S. Bickerton, M.P. Staiger. A critical review of all-cellulosecomposites, Journal of Materials Science, Vol. 47, No. 3, 1171-1186,2012.

[10] G. Kreindl. End of Life and Waste Management of Bio-based Products and Composites, 15th European Roundtable on Sustainable Consumption and Production, 2012.

[11] V. Fiore, A. Valenza, G. Bella. Artichoke (Cynara cardunculus L.) fibres as potential reinforcement of composite structures, Composites Science and Technology, Vol. 71, No.8, 1-32, 2011.

[12] N.R. Sewench, M.H. Samah,. Characteristic of Hybrid Chestnut Shell Fillers/ Epoxy Composite, The Journal of Engineering and Technology, Vol. 31, No.3, 368-380, 2013.

[13] D. Chensong, J.D. Ian. Flexural properties of macadamia nutshell particle reinforced polyester composites, Composites Part B: Engineering, Vol.43, No. 7, 2751-2756, 2012.

[14] C.S. Wu, H.T. Liao. The mechanical properties, biocompatibility and biodegradability of chestnut shell fibre and polyhydroxyalkanoate composites, Polymer Degradation and Stability, Vol.99, 274-282, 2014.

[15] FAO. Food and Agriculture Organization of the United Nations. (2013) Crop statistics. http://faostat.fao.org/beta/en/\#data/QC.

[16] M. Rokbi, H. Osmani, A. Imad, N. Benseddiq. Effect of Chemical treatment on Flexure Properties of Natural Fiber-reinforced Polyester Composite, Procedia Engineering, Vol. 10, 2092-2097, 2011.

[17] L. Ghali, S. Msahli, M. Zidi, F. Sakli. Effects of Fiber Weight Ratio, Structure and Fiber Modification onto Flexural Properties of Luffa-Polyester Composites, Advances in Materials Physics and Chemistry, Vol.1, 78-85, 2011.

[18] R. Mansour, M. Rokbia, H. Osmani, A. Imad, N. Benseddiq. Effect of Chemical treatment on Flexure Properties of Natural Fiber-reinforced Polyester Composite, Procedia Engineering, Vol.10, 2092-2097, 2011.

[19] K.L. Pickering, A. Abdalla, C. Jia, A.G. McDonald, R.A. Franich. The effect of silane coupling agents on radiata pine fibre for use in thermoplastic matrix composites, Composites: 
Part A, Vol. 34, 915-926, 2003.

[20] Y. Bulut, U. H. Erdoğan. Usability of Cellulose Based Natural Fibers as Reinforcement Materials In Composite Manufacturing, The Journal of Textiles and Engineers, Vol. 18, No.82, 26-35, 2011.

[21] D. Paukszta, S. Borysiak. The Influence of Processing and the
Polymorphism of Lignocellulosic Fillers on the Structure and Properties of Composite Materials, Materials, Vol.6, 2747-2767, 2013.

[22] A. Aruniit, J. Kers, K. Tall. Influence of filler proportion on mechanical and physical properties of particulate composite, Agronomy Research Biosystem Engineering, Special Issue, Vol. 1, 23-29, 2011. 